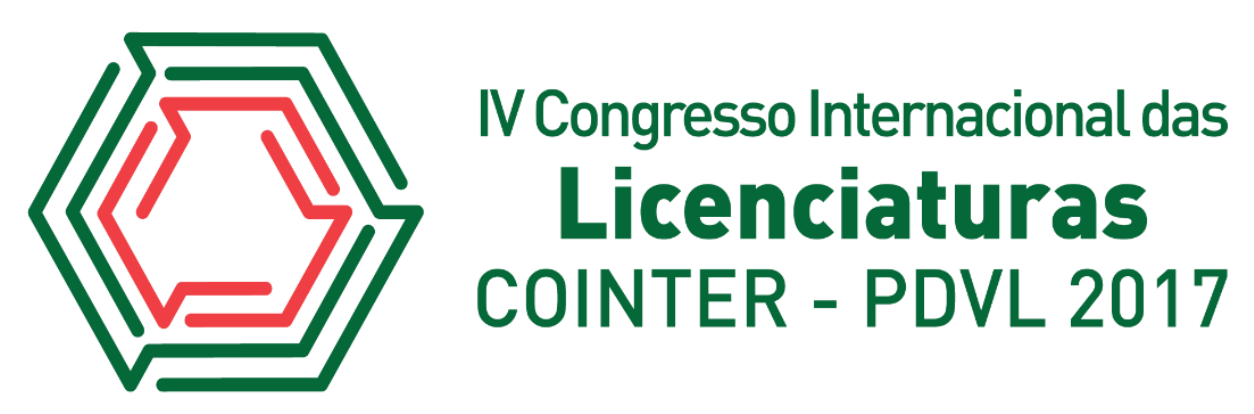

\title{
A MONITORIA FORTALECENDO A APRENDIZAGEM NA DISCIPLINA DE PRODUÇÃO ANIMAL
}

\author{
Apresentação: Pôster
}

\begin{abstract}
Amanda Fabrício Dantas ${ }^{1}$; Mário César de Lima²; Ana Patrícia Almeida Bezerra ${ }^{3}$
\end{abstract}
\section{Introdução}

A monitoria acadêmica tem um papel fundamental no ensino uma vez que auxilia no trabalho pedagógico das disciplinas, e o aluno monitor tem a vivencia de novas experiências pedagógicas auxiliando o professor nas aulas e contribuindo com a aprendizagem dos alunos, fazendo assim uma cooperação e todos saem fortalecidos no processo de ensino aprendizagem, os alunos tem a vantagem de ter um monitor sempre presente para tirar suas dúvidas sobre os conteúdos que foram visto na sala de aula em outro horário. Diante disto a monitoria colabora para a melhorias das notas dos exames realizados pelo professor contribuindo com o avanço na qualidade do ensino.

O conhecimento da produção animal é importante para os alunos dos cursos que compreende a área das ciências agrárias, no curso de bacharelado em agroecologia é uma disciplina obrigatória ofertada no primeiro período para que os alunos aprendam os princípios básicos da produção animal, nesta disciplina Nesta disciplina é abordado alguns assuntos como: Conceito de Zootecnia e Domesticação; Alimentação; Origem das Espécies e Classificação Zootécnica; Classificação das Aptidões e Funções Zootécnicas; Anatomia Comparada do Trato Gastrointestinal dos Animais Domésticos; Nomenclatura e Localização das regiões do corpo dos animais domésticos; Sistemas de criação. Esta disciplina demanda um pouco de dedicação por parte do professor, pois além de transmitir os conhecimentos teórico o professor precisa mostrar os sistemas de produção animal das mais variadas espécies para que esses alunos recém-chegados no mundo acadêmico conheça os tipos de espécie e produção existente. Neste sentido surge o importante papel do monitor colaborando com o professor no processo de ensino aprendizagem, e fica nítido que as

\footnotetext{
${ }^{1}$ Licenciatura em Ciências Agrárias, Universidade Federal da Paraíba, E-mail: amandadantas550@gmail.com

${ }^{2}$ Licenciatura em Ciências Agrárias, Universidade Federal da Paraíba, E-mail: mariocesarufpb@gmail.com

${ }^{3}$ Doutora em Zootecnia, Universidade Federal da Paraíba, E-mail: bezerraapa@gmail.com
} 
aulas práticas no qual os alunos visitam o sistema de produção adotados nos laboratórios do campus III apresentam maior participação nas aulas, como o aluno adquire uma certa autonomia para estudar aquelas espécies que despertam maior interesse, como também surge o interesse pelos estágios por parte dos alunos que é fundamental para sua formação acadêmica. Esse trabalho foi desenvolvido com o intuito de contribuir para melhoria do aprendizado dos alunos do curso de bacharelado em agroecologia.

\section{Fundamentação Teórica}

A monitoria é entendida como instrumento para a melhoria do Ensino de Graduação, através do estabelecimento de novas práticas e experiências pedagógicas que visam fortalecer a articulação entre teoria e prática e a integração curricular em seus diferentes aspectos. No entanto define-se também como o processo no qual os alunos monitores auxiliam seus colegas de curso a ter um bom desempenho na disciplina, por meio do processo de ensino aprendizagem sob a orientação direta de um docente (CONSELHO DE ENSINO E PESQUISA, 2009). A monitoria é de grande importância principalmente para aqueles alunos que estão ingressando em um curso de licenciatura, e ainda não tem certeza se é realmente a profissão que deseja ingressar, logo o aluno monitor irá adquirir novas experiências na sala de aula obtendo vários benefícios para o seu futuro. De acordo com Matoso (2013), o privilégio oferecido aos aprovados nos programas de monitoria torna-se de fundamental importância para a descoberta da vocação, ou não, pela docência, evitando, assim, que, no futuro, possam tornar-se profissionais descontentes com a carreira escolhida. De acordo com VICENZI, C. B. et al. (2016) O aluno monitor tem a oportunidade de conhecer melhor a disciplina escolhida, permitindo assim um benefício mútuo entre ele, o professor orientador e aos alunos que dela participam.

O programa de monitoria é de grande relevância para o desenvolvimento escolar, pois além de contribuir de forma significativa para a formação do aluno monitor, ajuda na retirada de duvidas apresentada pelos discentes sobre a disciplina cursada, ajudando a diminuir a evasão nos cursos de graduação e promovendo cada vez mais a troca de conhecimento. A monitoria, como procedimento pedagógico, demonstra sua utilidade, à medida que atende às dimensões "política, técnica e humana da prática pedagógica” (CANDAU, 1986, p.12-22). 


\section{Metodologia}

O trabalho foi desenvolvido no centro de ciências humanas sociais e agrárias campus III da UFPB. O plano de trabalho foi dividido em dois momentos:

Primeiro momento: ligado diretamente ao professor, auxiliando no planejamento e execução das atividades junto aos alunos da disciplina, através do aprofundamento do material teórico.

Segundo momento: trabalho do aluno-monitor junto aos alunos da disciplina, tendo como intenção auxiliar os discentes no esclarecimento de dúvidas e/ou aprofundamento da temática, conforme horários previamente agendados.

Plano de atividades desenvolvidas: Diante da realidade apresentada pelos alunos, o monitor exerceu as seguintes funções:

- Participou das aulas, auxiliando nas discussões e também na organização de material necessário para as atividades desenvolvidas;

- Planejamento das atividades que foram desenvolvidas junto aos alunos (aulas, seminários, atividades extraclasses...) e avaliação dos trabalhos; os horários para o atendimento aos discentes foram planejados para os esclarecimentos técnicos e práticos; como também houve o desenvolvimento de atividades teóricas e práticas.

Dizer qual a natureza da pesquisa (qualitativa, quantitativa), qual o tipo (etnográfica, experimental, estudo de caso, etc.) o campo de pesquisa e os sujeitos, quais instrumentos utilizados e qual o procedimento.

\section{Resultados e Discussões}

Durante a execução deste trabalho percebemos que monitoria estar se tornando indispensável para a formação dos alunos, uma vez que ela contribui para a iniciação à docência do aluno-monitor, mas também contribui no processo de ensino aprendizagem dos alunos proporcionando uma autonomia maior entre eles, buscando cada vez mais aprender sobre os assuntos trabalhados, logo despertando o espírito crítico e investigativo dos discentes. A medida que vai ocorrendo a busca da socialização dos conhecimentos com a participação dos alunos nas aulas o processo de ensino aprendizagem vai se tornando cada vez maior como mostra na figura 1. 
Figura 1: Alunos em aula no Laboratório de Cunicultura do CCHSA-UFPB. Fonte: Própria

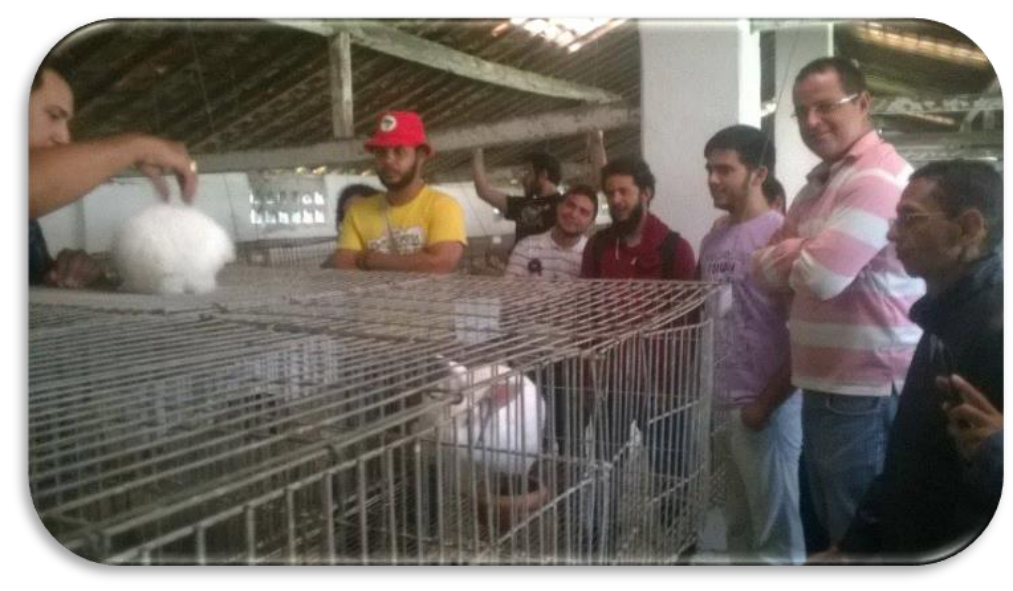

Na figura 1 observamos uma aula de produção animal na qual os alunos aprendem as principais raças e suas aptidões, os sistemas de criação e a importância da cunicultura na produção animal, tornando assim uma aula produtiva sempre despertando o interesse dos alunos. Com isto observamos o importante papel do monitor na colaboração junto com o professor nessas aulas, onde juntos podem construir e socializar o conhecimento. A monitoria acadêmica é um passo importante na vida de um estudante universitário, ela pode levá-lo a trilhar caminhos diferentes dos que havia planejado ao adentrar no mundo acadêmico (SOARES \& SANTOS). A figura 2 mostra a socialização dos conhecimentos para construção da aprendizagem no laboratório de suinocultura do CCHSA-UFPB.

Figura 2: alunos participando de aula e socializando o conhecimento no laboratório de suinocultura do CCHSA-UFPB. Fonte: Própria

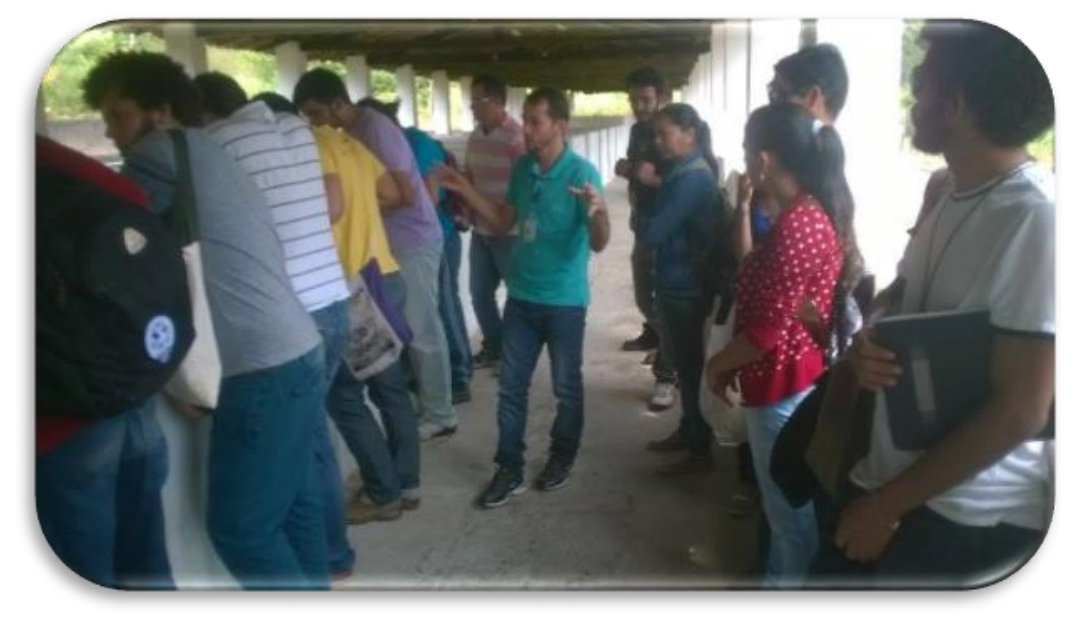

Esta socialização do conhecimento se torna uma ferramenta importante para o processo de ensino aprendizagem no qual os alunos participam das aulas expondo opiniões e assim faz uma 
construção mutua do conhecimento, que vai servir tanto para o aluno tirar boas médias nos exames avaliativos, como vai contribuir para o seu cotidiano pois a partir de uma socialização vários temas são abordados na área da produção animal como a qualidade da matéria prima para a alimentação dos animais o bem estar e a qualidade de carne, e poluição e impactos ambientais na produção são alguns temas geradores de discussão que contribui para a construção do conhecimento na aula sendo de extrema importância na formação acadêmica desses alunos como também contribui na formação de docência do aluno-monitor. Já para Assis FD, et al (2006), o exercício da monitoria é uma oportunidade para o estudante desenvolver habilidades inerentes à docência, aprofundar conhecimentos na área específica e contribuir com o processo de ensino-aprendizagem dos alunos monitorados. Diante disso percebemos a importância do programa de monitoria acadêmica para o desenvolvimento da educação e formação dos discentes.

\section{Conclusões}

A monitoria é um instrumento importante para aprendizagem dos alunos como também contribui para formação acadêmica do aluno-monitor promovendo uma maior interação no meio acadêmico para a construção dos conhecimentos promovendo uma melhoria na qualidade da educação.

\section{Referências}

CANDAU, V. M. F. A didática em questão e a formação de educadores-exaltação à negação: a busca da relevância. In: CANDAU, V. M. F. (org), A didática em questão. Petrópolis: Vozes, 1986, p. 12-22.

Conselho de ensino e pesquisa. Resolução $n^{\circ}$ 733, de 25 de agosto de 2009.

ASSIS, F. D, et al. Programa de monitoria acadêmica: percepções de monitores e orientadores. Rev. Enferm. Uerj, 2006; jul.-set;14(3):391-397.

MATOSO, Leonardo Magela Lopes. A importância da monitoria na formação acadêmica do monitor: um relato de experiência. 2013. Disponível em: https://repositorio.unp.br/index.php/catussaba/article/view/567>. Acesso em: 28 set. 2017.

SOARES, Moisés de Assis Alves; SANTOS, Kadidja Ferreira. A monitoria como subsídio ao processo de ensino-aprendizagem: o caso da disciplina administração financeira no CCHSA UFPB (S/D).

VICENZI, C. B. et al. A monitoria e seu papel no desenvolvimento da formação acadêmica. Rev. Ciênc. Ext. v.12, n.3, p.88-94, 2016. 